\title{
Investigation on the Pinch Point Position in Heat Exchangers
}

\author{
PAN Lisheng $^{1 *}$, SHI Weixiu ${ }^{2 * *}$
}

1. State Key Laboratory of High-temperature Gas Dynamics, Institute of Mechanics, Chinese Academy of Sciences, Beijing 100190, China

2. School of Environment and Energy Engineering, Beijing University of Civil Engineering and Architecture, Beijing 100044, China

(C) Science Press and Institute of Engineering Thermophysics, CAS and Springer-Verlag Berlin Heidelberg 2016

\begin{abstract}
The pinch point is important for analyzing heat transfer in thermodynamic cycles. With the aim to reveal the importance of determining the accurate pinch point, the research on the pinch point position is carried out by theoretical method. The results show that the pinch point position depends on the parameters of the heat transfer fluids and the major fluid properties. In most cases, the pinch point locates at the bubble point for the evaporator and the dew point for the condenser. However, the pinch point shifts to the supercooled liquid state in the near critical conditions for the evaporator. Similarly, it shifts to the superheated vapor state with the condensing temperature approaching the critical temperature for the condenser. It even can shift to the working fluid entrance of the evaporator or the supercritical heater when the heat source fluid temperature is very high compared with the absorbing heat temperature. A wrong position for the pinch point may generate serious mistake. In brief, the pinch point should be founded by the iterative method in all conditions rather than taking for granted.
\end{abstract}

Keywords: pinch point position, heat exchanger, heat transfer, phase transition, supercritical condition

\section{Introduction}

Heat exchanger is an important industrial equipment which is widely used. Phase transformation is an important state change process. This process usually occurs in the heat exchanger, yet there are also many conditions without phase transformation. In thermodynamic cycle system, heat exchanger is used as evaporator, condenser, supercritical heater, and so on.

The pinch point is an important parameter for analyzing heat transfer in heat exchanger. In the analysis, it also impacts on the cycle performance of the thermodynamic cycles, like the refrigeration cycle and the organic Rankine cycle (ORC). Saleh et al. [1] proposed a pinch point analysis method which is widely used in the ORC theoretical analysis [2-4]. Using pinch point ana- lysis method, the operation parameters of the heat exchangers can be related to the cycle parameters and the investigation on the whole performance of the ORC system can be carried out. Chen et al. [5] paid attention to the zeotropic mixture working fluids which gave perfect glide matching of heat transfer fluids and working fluids. However, for some zeotropes, the pinch points might still appear in the evaporating or condensing process and there existed certain limits to avoid the pinch points [6, 7]. Liu et al. [8] carried out experimental studies on the pinch point in the heat exchangers which are used for the high temperature heat pump. They pointed out that a higher COP value can be given by the zeotropic mixture having a smaller maximum temperature difference in the condenser and a smaller minimum temperature difference in the evaporator. Zebian et al. [9] presented a double- 


\begin{tabular}{llll}
\hline Nomenclature & & & \\
$M$ & molar mass $(\mathrm{g} / \mathrm{mol})$ & Greek letters & \\
$p$ & pressure $(\mathrm{MPa})$ & $\rho$ & density $\left(\mathrm{kg} / \mathrm{m}^{3}\right)$ \\
$r p$ & reduced pressure & Subscripts & \\
$t$ & temperature $\left({ }^{\circ} \mathrm{C}\right)$ & $\mathrm{c}$ & critical \\
$\dot{m}$ & mass flow rate $(\mathrm{kg} / \mathrm{s})$ & $\mathrm{b}$ & boiling \\
$s$ & specific entropy $\left(\mathrm{J} /\left(\mathrm{kg} \cdot{ }^{\circ} \mathrm{C}\right)\right)$ & $\mathrm{p}$ & constant pressure \\
$r$ & ratio & $\mathrm{m}$ & mass flow rate \\
$A L T$ & atmospheric lifetime & $\mathrm{hsf}$ & heat source fluid \\
$O D P$ & ozone depression potential & $\mathrm{csf}$ & cold source fluid \\
$G W P$ & global warming potential & Superscripts & \\
& &, & inlet \\
& &, & outlet \\
\hline
\end{tabular}

pinch criterion for the closed feed water heaters of the regenerative Rankine cycles. The criterion simplified the optimization procedure and resulted in significant efficiency increase with fixed heat exchanger area. Li et al. [10] analyzed the influence of the pinch point temperature difference on the performance of ORC which is used in recovering the low temperature waste heat of the flue gas. Fischer [11] compared trilateral cycles and ORC and pointed out that the pinch point located at different position in different cases.

From the previous studies, it can be concluded that the pinch point plays an important role in the analysis on the thermodynamic cycle and the pinch point position may shift in different cases. If the wrong position is used, large error or even wrong result may appear in the theoretical studies. For example, in the evaporator the pinch point usually locates at the fluid bubble point, whereas it shifts to the supercooled state with near-critical pressure. If this shift was not taken note of, an obviously jump for the cycle performance could be achieved in the nearcritical condition, as shown in Fig. 1a [12]. However, in fact, the parameters varied continuously in the transition from the subcritical conditions to the supercritical conditions, as shown in Fig. 1b [13].

The pinch point position is of importance for analyzing the thermodynamic cycle. Nevertheless, the transition of the pinch point didn't attract enough attention. The position in the evaporator and the supercritical heater depends on several factors, such as heat source parameters, fluid parameters and fluid properties. For the condenser, it depends on cold source parameters, fluid parameters and fluid properties. This article studies on the position in different cases and provided the error caused by misjudgment of the position.

\section{Method}

Phase change heat transfer has good performance and is widely used in many industry processes, such as the refrigeration cycle system and power cycle system. Working fluid evaporates from liquid to vapor in evaporator and condensed in condenser. Pinch point is of importance

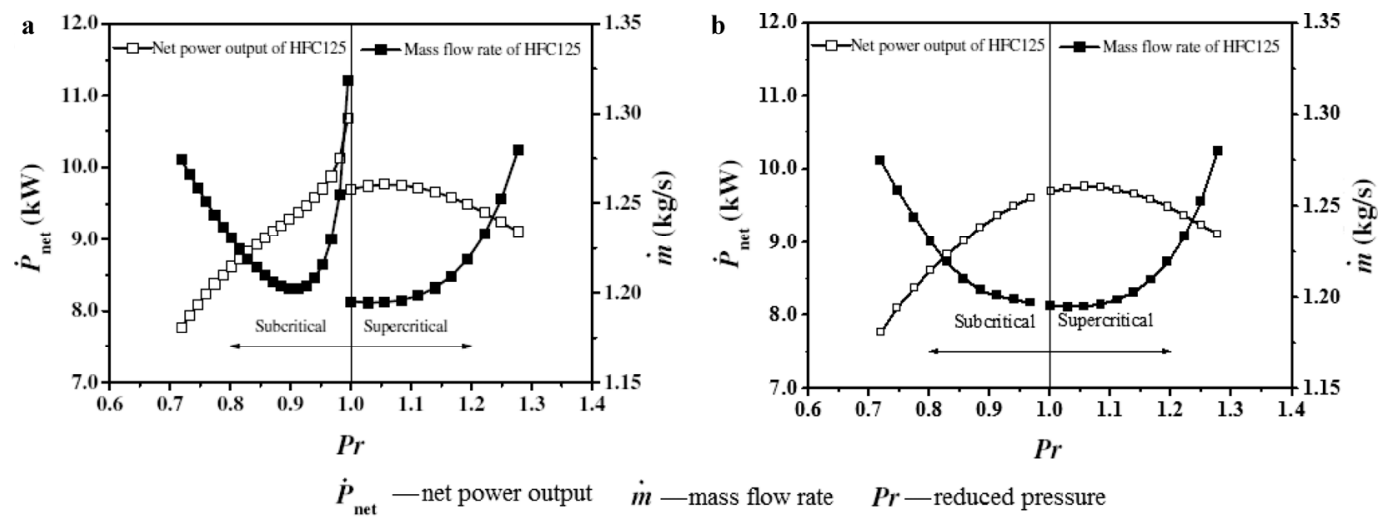

Variation of net power generation and mass flow rate of working fluid with evaporating (heating) pressure.

Fig. 1 The impact of the misjudgment of the pinch point position on the analysis result $[12,13]$ (a. misjudgment; b. correct judgement) 
for analyzing the heat transfer process. The pinch point is usually specified as the bubble point in evaporator, as shown in Fig. 2a, and the dew point in condenser. In some conditions, pinch point indeed locates at the saturation point. However, it's wrong to take it for granted that the pinch point always locates there. The position may transfer with conditions. For example, it transfers from the bubble point to a supercooled state with near-critical pressure. The similar phenomenon also occurs in condenser. Fig. $2 b$ also shows the heat transfer process in a supercritical heater in which working fluid absorbs heat energy at supercritical pressure. There isn't phase change for working fluid in the heater, but it is also taken account of in the article. This type heat transfer process is used in transcritical cycle systems and is also more complicated than single phase heat transfer.

In summary, the pinch point position should be achieved by detailed iterative computation in the analysis of the heat transfer process.

In this article, several cases is considered based on five organic fluids, namely, HFC41, HFC125, HFC143a, FC218 and HFC245fa. These fluids present phase change or keep in supercritical pressure while the heat source fluid and cold source fluid keep single phase. These considered fluids are environment friendly and have zero ODP. Their basic thermal properties and environment properties are shown in Table 1 [14]. In the analysis, properties of the working fluid are obtained from REFPROP9.0 [15] that can reveal detailed state parameters with inputting a few state parameters. Though only a few fluids are analyzed, the result about pinch point position is universal.

In order to acquire accurate position of the pinch point, iterative procedure is established for evaporator, as shown in Fig. 3a. There are five input parameters, namely, the heat source fluid temperature, the fluid inlet temperature, the evaporating temperature, the fluid outlet superheat degree and the pinch point temperature difference. Firstly, a value needs to be initialized for the ratio of the working fluid flow rate to the heat source flow rate. Secondly, a series of water state and fluid state in the evaporator can be obtained by the law of energy conservation. In each

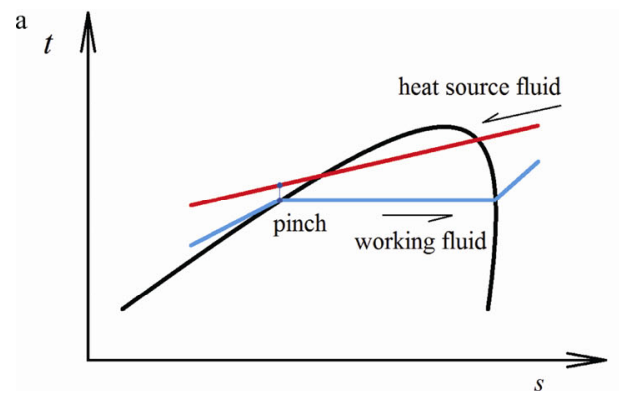

heat transfer unit, the heat absorbed by the working fluid is equal to heat released by the heat source fluid. Thirdly, pinch point position for this considered condition can be obtained by comparing temperature difference in this series state. Fourthly, it should be judged whether the obtained pinch point temperature difference is equal to the specified pinch point temperature difference or not. If the obtained one is equal to the specified one, the pinch point position for the specified pinch point temperature difference and the mass flow rate ratio are founded. Otherwise, the mass flow rate ratio is revised to iterate again. As shown in Fig. 3b, the iterative procedure for supercritical heater is similar to the evaporator. The difference is that the fluid outlet temperature is specified for the supercritical heater while should be calculated by summing the evaporating temperature and the superheat degree for the evaporator. Fig. 3c shows the method for searching the pinch point position in the condenser. Firstly, all necessary known data are inputted and the ratio of the working fluid flow rate to the cold source fluid flow rate is initialized. Secondly, a series of water state and fluid state in the condenser is obtained by the law of energy conservation. Then, the pinch point position is obtained by comparing the cold source fluid temperature and the working fluid temperature. Fourthly, the program judges whether the pinch point temperature difference meets the requirement or not and decides the next action.

\section{Results and discussion}

The inlet temperature of the two fluid impacts the pinch point position in the heat exchangers. Additionally, the other factors needed to be considered are the properties of the working fluid, especially the specific enthalpy. In this article, pinch point position in four cases is analyzed. According to a specific pinch point temperature difference, the accurate pinch point information can be achieved by the iterative computation. Then the pinch point information is compared with the bubble point information or dew point information in order to analyze the error of taking for granted.

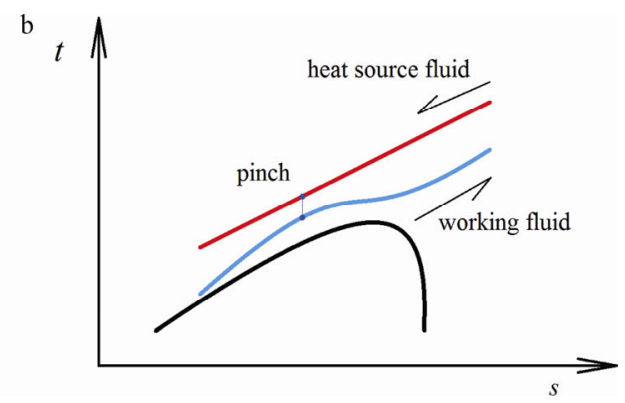

Fig. 2 Sketch map for the pinch point position in the evaporator and the supercritical heater (a. in the evaporator; b. in the supercritical heater) 
Table 1 Basic thermal properties and environment properties of considered fluids [14]

\begin{tabular}{lccccccc}
\hline & \multicolumn{3}{c}{ Basic thermal properties } & \multicolumn{3}{c}{ Environmental properties } \\
\cline { 2 - 8 } Substance & $M$ & $t_{b}$ & $t_{c}$ & $p_{c}$ & $A L T$ & $O D P$ & GWP \\
\cline { 2 - 8 } & $\mathrm{g} / \mathrm{mol}$ & ${ }^{\circ} \mathrm{C}$ & ${ }^{\circ} \mathrm{C}$ & $\mathrm{MPa}$ & $\mathrm{yr}$ & $/$ & $100 \mathrm{yr}$ \\
\hline HFC41 & 34.03 & -78.3 & 44.1 & 5.90 & 2.4 & 0 & 92 \\
HFC125 & 120.02 & -48.1 & 66.0 & 3.62 & 29 & 0 & 3500 \\
HFC143a & 84.04 & -47.2 & 72.7 & 3.76 & 52 & 0 & 4470 \\
FC218 & 188.02 & -36.8 & 71.9 & 2.64 & 2600 & 0 & 8830 \\
HFC245fa & 134.05 & 15.1 & 154.0 & 3.65 & 7.6 & 0 & 1030 \\
\hline
\end{tabular}

\section{Case I: low heat source temperature \& constant su- perheat degree}

This subsection gives the analysis results for the case with low heat source temperature and constant superheat degree in evaporator. In another word, the heat source temperature is only a little higher than the working fluid. The working fluid at the evaporator exit has constant superheat degree, which is to say that its temperature is higher than the evaporating temperature by constant value. The heat source fluid is water. The parameters of the considered conditions are shown in Table 2. The considered working fluids include HFC125, HFC143a and FC218. In this case, the working fluid evaporates at the temperature which is in the range from $50^{\circ} \mathrm{C}$ to its critical temperature.

There are many sizes of the heat exchangers, as well as the types. Therefore, it is an important problem that how to represent the pinch point position for the heat exchanger. In this article, the fluid which represents phase transition or is under supercritical pressure is considered as the important one. The heat source fluid or the cold source fluid is unimportant. Consequently, a parameter of the important fluid is selected to show the position of the heat transfer pinch point. The parameter, specific entropy, varies with the fluid being heated or cooled. Then, there is a one-to-one match between the specific entropy and the position.

Fig. 4 shows the pinch point position, as well as the fluid bubble point position that is also represented by the specific entropy. When the evaporating temperature is low, the pinch point position locates at the bubble point. However, with increasing the evaporating temperature, the pinch point position shifts to the supercooled state which has lower specific entropy than the bubble point. For HFC125, HFC143a and FC218, the pinch point position begins to deviate from the bubble point with the evaporating temperature of $58^{\circ} \mathrm{C}, 68^{\circ} \mathrm{C}$ and $65^{\circ} \mathrm{C}$, respectively. As shown in Fig. 5, when the evaporating temperature is low, it creates little error to replace pinch point with bubble point. However, it creates serious error or mistake when the evaporating temperature exceeds

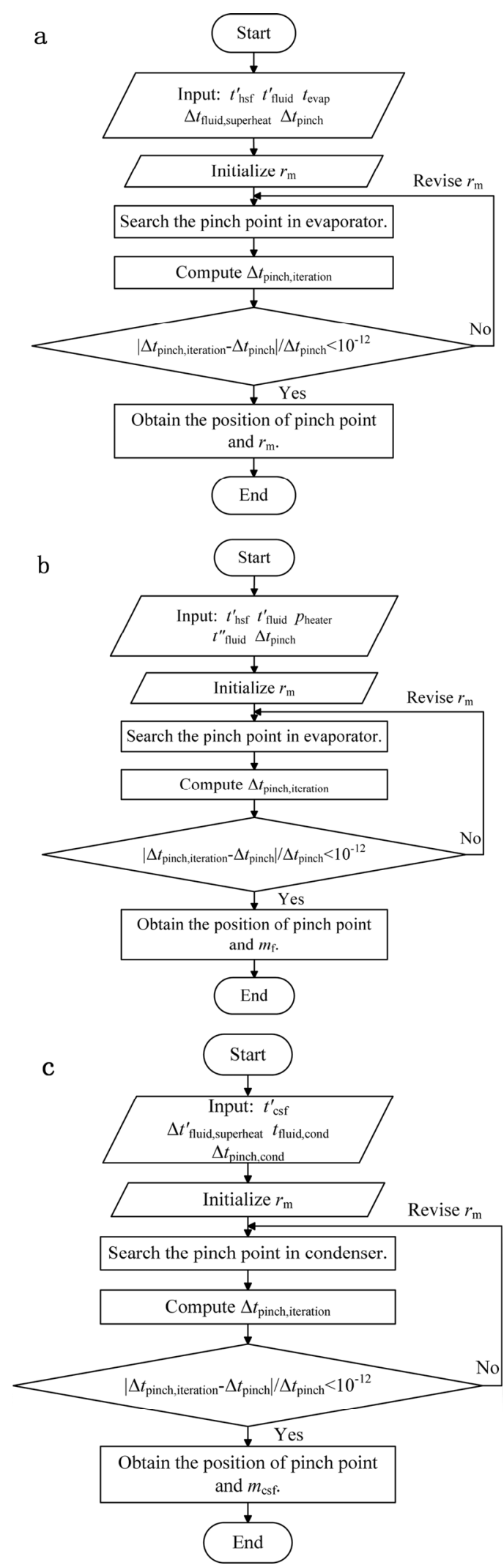

Fig. 3 Block diagram for finding the pinch point position in the evaporator, the supercritical heater and the condenser (a. in the evaporator; $b$. in the supercritical heater; c. in the condenser) 
Table 2 Parameter setting for the case I

\begin{tabular}{cccccccc}
\hline Item & $t_{\text {hsf }}^{\prime}$ & $c_{\mathrm{p}, \text { hsf }}$ & $\rho_{\text {hsf }}$ & $t_{\text {fluid }}^{\prime}$ & $t_{\text {fluid,evap }}$ & $\Delta t^{\prime \prime}$ fluid,superheat & $\Delta t_{\text {pinch }}$ \\
\hline Unit & ${ }^{\circ} \mathrm{C}$ & $\mathrm{kJ} /\left(\mathrm{kg} \cdot{ }^{\circ} \mathrm{C}\right)$ & $\mathrm{kg} / \mathrm{m}^{3}$ & ${ }^{\circ} \mathrm{C}$ & ${ }^{\circ} \mathrm{C}$ & ${ }^{\circ} \mathrm{C}$ & ${ }^{\circ} \mathrm{C}$ \\
\hline Value & 90 & 4.19 & 1000 & 35 & $50-t_{\text {critical }}$ & 5.0 & 5.0 \\
\hline
\end{tabular}

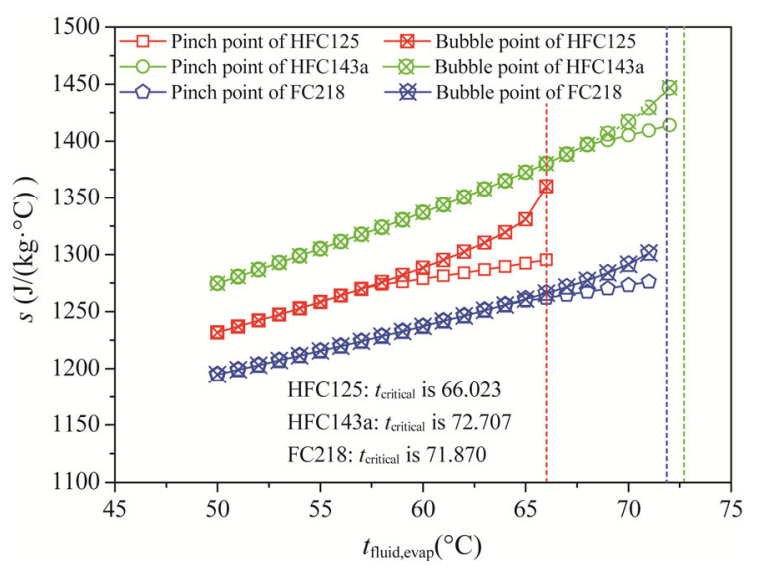

Fig. 4 Variation of the pinch point position and the bubble point position with the evaporating temperature

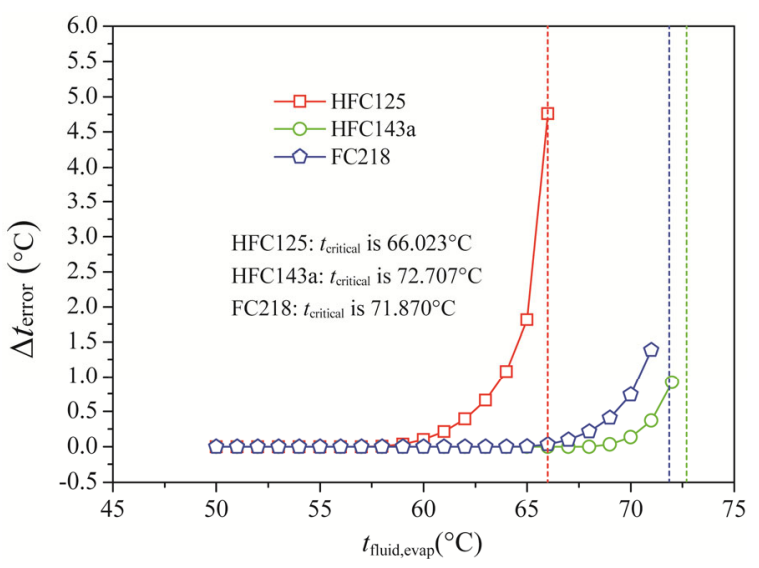

Fig. 5 Variation of the temperature difference between the pinch point and the bubble point with the evaporating temperature

each limit temperature. The error increases with increasing the evaporating temperature, especially in the near critical conditions. For example, for HFC125, when the evaporating temperature is $66^{\circ} \mathrm{C}$ (approaching critical temperature), the pinch point temperature difference is $5^{\circ} \mathrm{C}$ and the bubble point temperature difference is $9.76^{\circ} \mathrm{C}$. The error even reaches $4.76^{\circ} \mathrm{C}$. The accuracy and the reliability will be greatly reduced by taking it for granted that the pinch point still locates at the bubble point in the near critical condition.

Case II: low heat source temperature $\&$ constant outlet temperature

In order to reveal the transition of the pinch point po- sition in near critical conditions, the outlet temperature is specified as a constant value, $80^{\circ} \mathrm{C}$, for the working fluid. Meanwhile, the condition varies from subcritical pressure to supercritical pressure. When the working fluid evaporates under subcritical pressure, the heat exchange is named evaporator. Nevertheless, the phase change never occurs under supercritical pressure. Thus the name of supercritical heater must be used to replace the evaporator in that condition. In this case, the heat source temperature is also only a little higher than the working fluid. The other parameters of the considered conditions are shown in Table 3. The considered working fluids are HFC125, HFC143a and FC218.

As shown in Fig. 6, for all the three fluids in the subcritical conditions, the pinch point begins to shift from the bubble point under the reduced pressure of $0.90,0.93$, and 0.91 , respectively. The pinch point position shifts smoothly as the condition shifts from the subcritical pressure to supercritical pressure. Fig. 7 shows the temperature of the two heat transfer fluids with the specific entropy of the major fluid. When the reduced pressure of HFC125 is 0.70, the minimum temperature difference of the two heat transfer fluids occurs at the bubble point. As the reduced pressure is 0.95 , the pinch point shifts to the supercooled state. In the supercritical condition with the reduced pressure 1.2, pinch point locates at the supercritical state. As also shown in Fig. 6, the pinch point of HFC125 shifts to right (the specific entropy increases with rising the reduced pressure). However, HFC143a and FC218 give a different trend. Their pinch point shifts

Table 3 Parameter setting for the case II

\begin{tabular}{cccccccc}
\hline Item & $t_{\text {hsf }}^{\prime}$ & $c_{\mathrm{p}, \text { hsf }}$ & $\rho_{\text {hsf }}$ & $t_{\text {fluid }}^{\prime}$ & $r p_{\text {fluid,heat }}$ & $t^{\prime \prime}$ fluid & $\Delta t_{\text {pinch }}$ \\
\hline Unit & ${ }^{\circ} \mathrm{C}$ & $\mathrm{kJ} /\left(\mathrm{kg} \cdot{ }^{\circ} \mathrm{C}\right)$ & $\mathrm{kg} / \mathrm{m}^{3}$ & ${ }^{\circ} \mathrm{C}$ & - & ${ }^{\circ} \mathrm{C}$ & ${ }^{\circ} \mathrm{C}$ \\
\hline Value & 90 & 4.19 & 1000 & 35 & $0.6-1.2$ & 80 & 5.0 \\
\hline
\end{tabular}

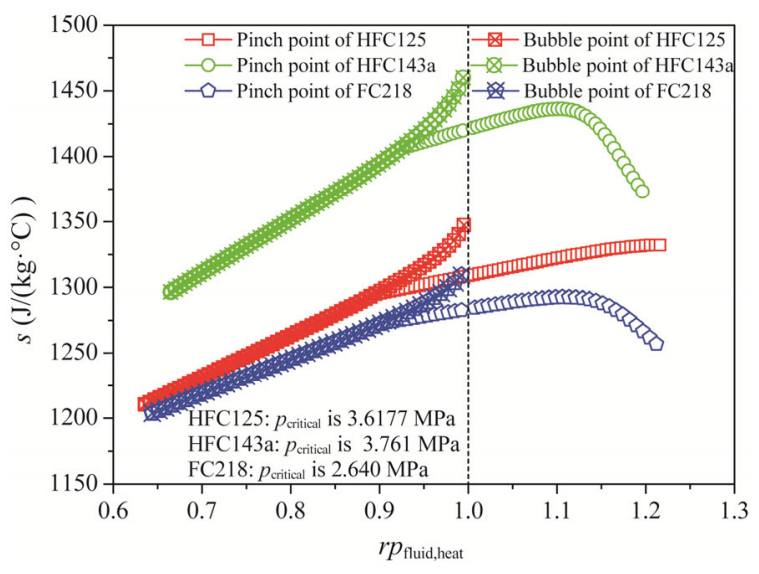

Fig. 6 Variation of the pinch point position and the bubble point position (subcritical conditions) with the reduced pressure 
to right firstly and then return to left, which leads a maximum specific entropy. The position of the pinch point depends on the shape of the isobar and the heat source. With constant heat transfer, the transition of the isobar determines the shift law of the pinch point.

\section{Case III: high heat source temperature \& constant superheat degree}

With very high heat source temperature, different rules are achieved for the pinch point position. In this case, the temperature difference of the two fluids is much higher than that in the above two cases. The inlet temperature of the heat source temperature is $280^{\circ} \mathrm{C}$ which is much higher than evaporating temperature, e.g. $145^{\circ} \mathrm{C}$. It should be noted that the heat source fluid is thermal oil rather than water. Liquid thermal oil can provide higher temperature than $100^{\circ} \mathrm{C}$. Still, the superheat degree at the evaporator exit keeps constant. The working fluid is HFC245fa in this case. The other parameters are shown in Table 4.

In the above subsection, the pinch point locates in the heat exchanger. However, with increasing temperature of the heat source fluid, the pinch point shifts to the entrance of the evaporator for the working fluid, as shown in Fig. 8. It will create great error to replace the pinch point with the bubble point because these two points deviate from each other seriously in this case. It should be noted that the pinch point may shift to left if the thermal

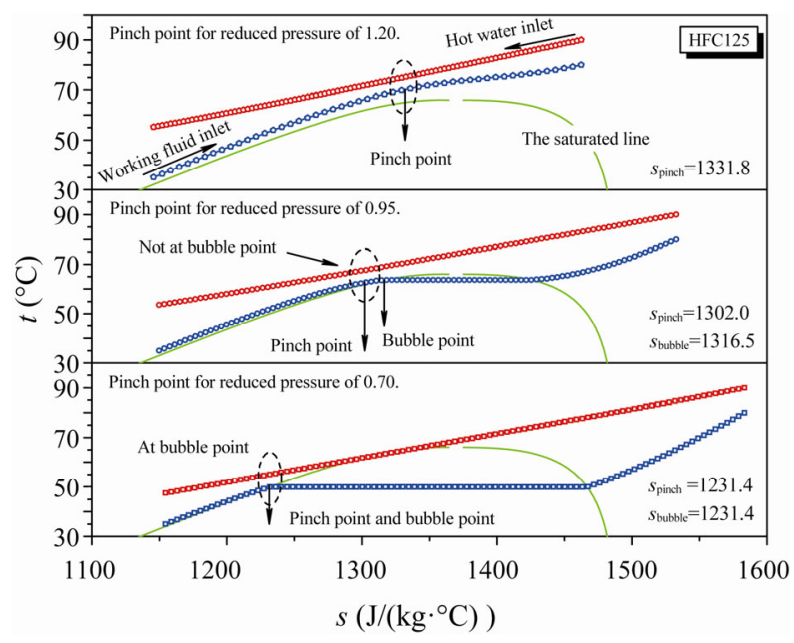

Fig. 7 The temperature profiles and the pinch point positions for different conditions in the evaporator (or the supercritical heater)

Table 4 Parameter setting for the case III

\begin{tabular}{ccccccc}
\hline Item $t_{\text {hsf }}^{\prime}$ & $c_{\mathrm{p} \text {, hsf }}$ & $\rho_{\text {hsf }}$ & $t_{\text {fluid }}^{\prime}$ & $t_{\text {fluid, evap }}$ & \multicolumn{2}{c}{$\Delta t^{\prime \prime}{ }_{\text {fluid,superheat }} \Delta t_{\text {pinch }}$} \\
\hline Unit ${ }^{\circ} \mathrm{C}$ & $\mathrm{kJ} /\left(\mathrm{kg} \cdot{ }^{\circ} \mathrm{C}\right)$ & $\mathrm{kg} / \mathrm{m}^{3}$ & ${ }^{\circ} \mathrm{C}$ & ${ }^{\circ} \mathrm{C}$ & ${ }^{\circ} \mathrm{C}$ & ${ }^{\circ} \mathrm{C}$ \\
\hline Value 280 & 2.3 & 790 & 35 & $85,120,145$ & 5.0 & 10.0 \\
\hline
\end{tabular}

oil temperature decreases or the evaporating temperature increases, which is also indicated in Fig. 7. From the analysis of heat transfer in evaporator or supercritical heater, the pinch point position depends on several factors, namely, heat source parameters, fluid parameters and fluid properties. The accurate information of the pinch point should be obtained by the iterative method which is shown in Fig. 3a and Fig. $3 b$ other than taking for granted.

\section{Case IV: pinch point position in condenser}

The above analysis focuses on pinch point in evaporator and supercritical heater. In specific conditions like near critical condition, pinch point in condenser gives similar results, which is usually neglected.

This subsection releases the variation of the pinch point position in condenser. HFC41 is selected as working fluid in this case. The other parameters are shown in Table 5.

As shown in Fig. 9, when the condensing temperature is low, the pinch point in the condenser coincides with the fluid dew point. However, the pinch point begins to deviate from the fluid dew point with the condensing temperature of about $38^{\circ} \mathrm{C}$. The deviation degree ascends with increasing the condensing temperature. As shown in Fig. 10, when the condensing temperature is $32^{\circ} \mathrm{C}$, the pinch point locates at the fluid dew point. When the condensing temperature is $40^{\circ} \mathrm{C}$, the pinch point shifts to the

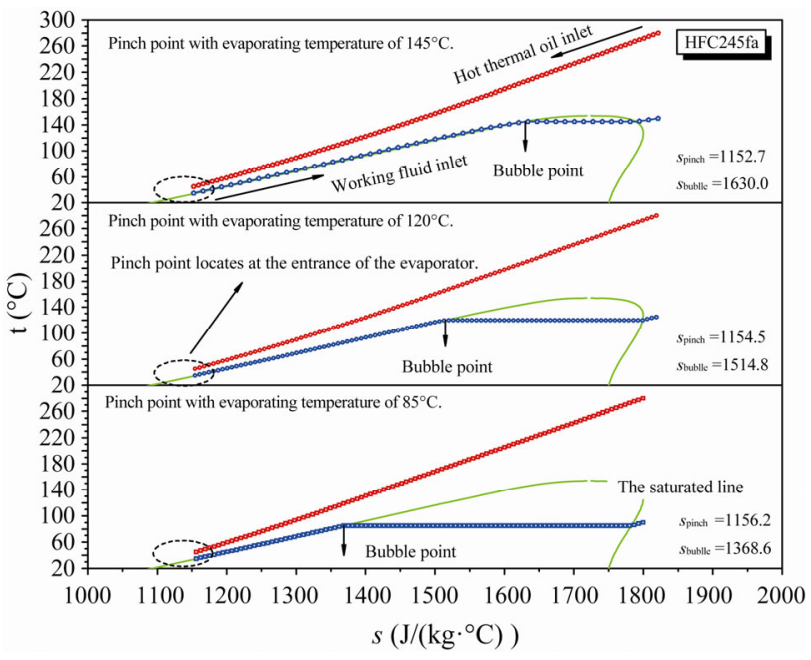

Fig. 8 Temperature profiles and the pinch point positions for different conditions in the evaporator.

Table 5 Parameter setting for the case IV

\begin{tabular}{ccccccc}
\hline Item & $t_{\text {csf }}^{\prime}$ & $c_{\text {p,csf }}^{\prime}$ & $\rho_{\text {csf }}$ & $\Delta t_{\text {fluid, superheat }}$ & $t_{\text {fluid, cond }}$ & $\Delta t_{\text {pinch }}$ \\
\hline Unit & ${ }^{\circ} \mathrm{C}$ & $\mathrm{kJ} /\left(\mathrm{kg} \cdot{ }^{\circ} \mathrm{C}\right)$ & $\mathrm{kg} / \mathrm{m}^{3}$ & ${ }^{\circ} \mathrm{C}$ & ${ }^{\circ} \mathrm{C}$ & ${ }^{\circ} \mathrm{C}$ \\
\hline Value & 20 & 4.19 & 100 & 10.0 & $30-41$ & 5.0 \\
\hline
\end{tabular}




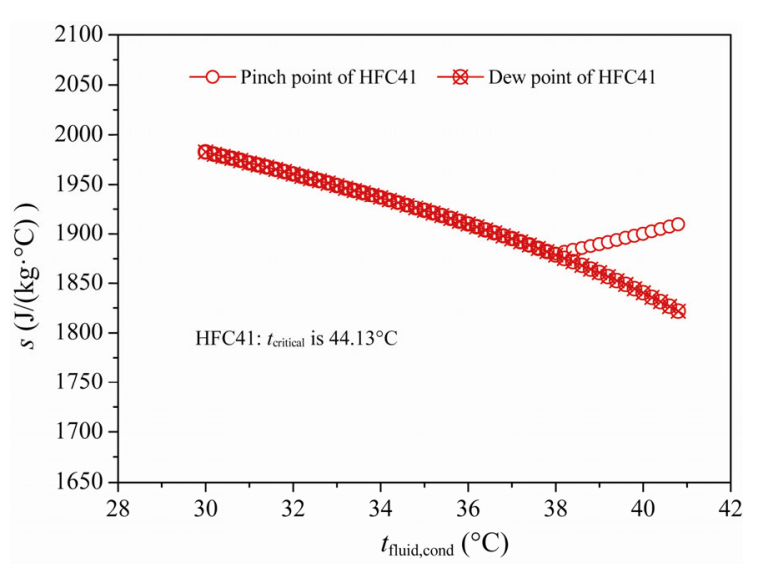

Fig. 9 Variation of the pinch point position and the dew point position with the condensing temperature.

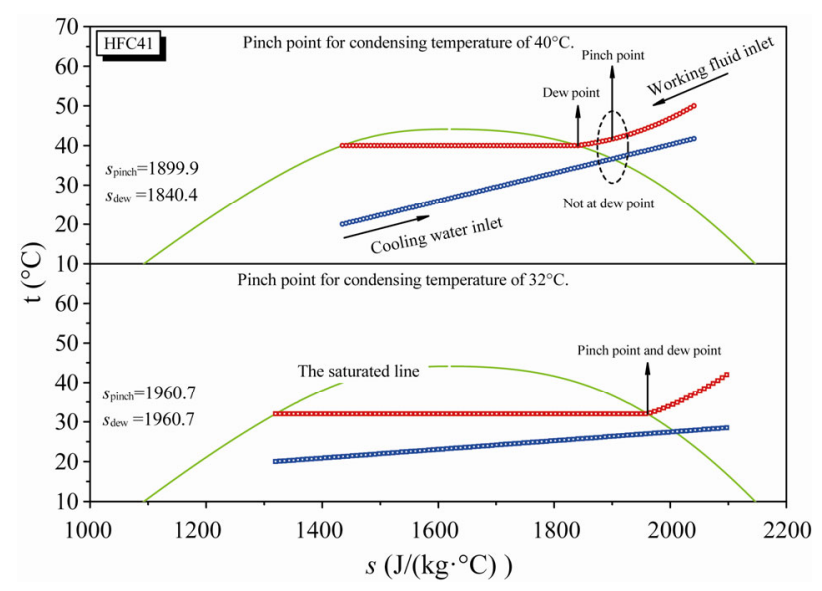

Fig. 10 Temperature profiles and the pinch point positions for different conditions in the condenser.

superheated vapor state. This variation is caused by the increase of the condensing temperature and the shape of the fluid isobar. Therefore, the pinch point in the condenser should also be obtained by the iterative method as shown in Fig. $3 \mathrm{c}$ rather than taking for granted.

\section{Concluding Remarks}

Heat exchangers are widely used in industry. Phase transformation usually occurs in heat exchangers for thermodynamic cycle like the refrigeration cycle and the organic Rankine cycle. The pinch point is a significant parameter for analyzing the heat transfer. This article carries out research on its position and the transition law. The position in the evaporator and the supercritical heater depends on several factors, such as heat source parameters, fluid parameters and fluid properties. For the condenser, it depends on cold source parameters, fluid parameters and fluid properties.

(1) In most cases, the pinch point locates at the bubble point of the working fluid. One requirement is that the heat source fluid temperature is not too high compared with the absorbing heat temperature. The other one is that the absorbing heat reduced pressure is not too close to 1.0. In other word, the working fluid absorbs heat in subcritical condition that is far from the near critical condition.

(2) The pinch point shifts to the supercooled liquid state in the near critical conditions. The additional requirement is that the heat source fluid temperature is not too high. The pinch point moves smoothly as the condition transits from the subcritical condition to the supercritical condition.

(3) In the condition with very high heat source fluid temperature, the pinch point gives a very different result. It locates at the working fluid entrance of the evaporator or the supercritical heater.

(4) The transition phenomenon also appears in the condenser. The pinch point locates at the fluid dew point when the cold source fluid temperature is not too low compared with releasing heat temperature and the condensing temperature is not too high to approach the critical temperature. However, it shifts to the superheated vapor state with increasing the condensing temperature.

\section{Acknowledgement}

Project 51306198 supported by National Natural Science Foundation of China is gratefully acknowledged. Thomas Tartière who worked at Enertime in Paris reminded me of the importance of confirming pinch point position.

\section{References}

[1] Saleh B, Koglbauer G, Wendland M, Fischer J. Working fluids for low-temperature organic Rankine cycles. Energy 2007; 32(7): 1210-1221.

[2] Karellas S, Schuster A, Leontaritis AD. Influence of supercritical ORC parameters on plate heat exchanger design. Appl Therm Eng 2012; 33-34: 70-76.

[3] He C, Liu C, Gao H, Xie H, Li YR, Wu S, Xu J. The optimal evaporation temperature and working fluids for subcritical organic Rankine cycle. Energy 2012; 38(1): 136-143.

[4] Ryms M, Pyś T, Klugmann-Radziemska E. Adapting the pinch point analysis to improve the ORC design process. Int J Energy Res 2013; DOI: 10. 1002/er.3011.

[5] Chen H, Goswami DY, Rahman MM, Stefanakos EK. A supercritical Rankine cycle using zeotropic mixture working fluids for the conversion of low-grade heat into power. Energy 2011; 36(1): 549-555.

[6] Venkatarathnam G, Mokashi G, Murthy SS. Occurrence of pinch points in condensers and evaporators for zeo- 
PAN Lisheng et al. Investigation on the Pinch Point Position in Heat Exchangers

tropic refrigerant mixtures. Int J Refrig 1996; 19(6): 361368.

[7] Venkatarathnam G, Murthy SS. Effect of mixture composition on the formation of pinch points in condensers and evaporators for zeotropic refrigerant mixtures. Int J Refrig 1999; 22(3): 205-215.

[8] Liu Z, Zhao L, Zhao X, Li H. The occurrence of pinch point and its effects on the performance of high temperature heat pump. Appl Energ 2012; 97(9): 869-875.

[9] Zebian H, Mitsos A. A double-pinch criterion for regenerative Rankine cycles. Energy 2012; 40(1): 258-270.

[10] Li YR, Wang JN, Du MT. Influence of coupled pinch point temperature difference and evaporation temperature on performance of organic Rankine cycle. Energy 2012; 42(1): 503-509.
[11] Fischer J. Comparison of trilateral cycles and organic Rankine cycles. Energy 2011; 36(10): 6208-6219.

[12] Pan L, Wang H, Shi W. Performance analysis in nearcritical conditions of organic Rankine cycle. Energy 2012; 37(1): 281-286.

[13] Pan L. Optimization of Organic Rankine Cycle and Investigation on Performance of Radial Flow Turbine for Power Generation with Low Grade Heat Source. Doctoral Dissertation, Tianjin University, Tianjin, 2012.

[14] Calm JM, Hourahan GC. Refrigerant data summary update. HPAC Engineering 2007; 79(1): 50-64.

[15] Lemmon EW, Huber ML, McLinden MO. NIST Standard Reference Database 23, Reference Fluid Thermodynamic and Transport Properties (REFPROP), version 9.0. National Institute of Standards and Technology 2010. 